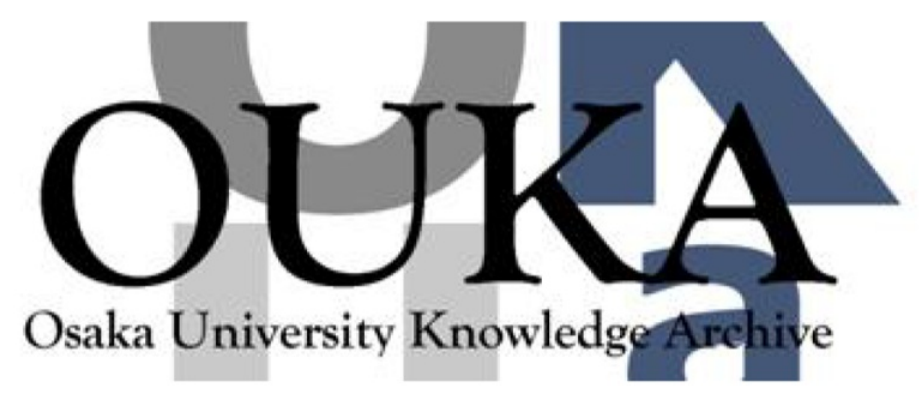

\begin{tabular}{|c|l|}
\hline Title & $\begin{array}{l}\text { Cryostat to provide a solid deuterium layer in } \\
\text { a plastic shell for the Gekko XII glass laser } \\
\text { system }\end{array}$ \\
\hline Author(s) & Norimatsu, T.; Ito, H.; Chen, C. et al. \\
\hline Citation & $\begin{array}{l}\text { Review of Scientific Instruments. 63(6) p. 3378- } \\
\text { p.3383 }\end{array}$ \\
\hline Issue Date & $1992-06$ \\
\hline oaire:version & VoR \\
\hline URL & https://hdl. handle. net/11094/3454 \\
\hline rights & \\
\hline Note & \\
\hline
\end{tabular}

Osaka University Knowledge Archive : OUKA

https://ir. Library. osaka-u. ac. jp/

Osaka University 


\title{
Cryostat to provide a solid deuterium layer in a plastic shell for the Gekko XII glass laser system
}

\author{
T. Norimatsu, H. Ito, ${ }^{\text {a) }}$ C. Chen, M. Yasumoto, M. Tsukamoto, K. A. Tanaka, \\ T. Yamanaka, and S. Nakai \\ Institute of Laser Engineering, Osaka University, 2-6, Yamada-Oka, Suita, Osaka 565, Japan
}

(Received 2 October 1991; accepted for publication 24 February 1992)

\begin{abstract}
A system to provide a liquid or solid deuterium shell target with a plastic ablator for laser implosion experiments was developed. The system is capable of filling a plastic capsule with deuterium gas of $11 \mathrm{MPa}$ at room temperature at the firing position in the target chamber. Then, the target is cooled down to a cryogenic temperature to form a uniform liquid or solid fuel layer inside without exposing it to the atmosphere. Details of the system, tensile strength of polystyrene shells at low temperature, and the residual vapor pressure in the central void of the target at the laser irradiation are described.
\end{abstract}

\section{INTRODUCTION}

A cryogenically cooled pellet with shell-structured fuel (termed cryogenic target) is essentially important for laser fusion research. Two types of cryogenic targets have been developed. The first one is a cryogenic target with a glass microballoon as a container of solid or liquid fuel. This target is fabricated in a cryostat installed in a target chamber for laser fusion experiment by cooling the glass microballoon pressurized with fuel gas elsewhere. ${ }^{1-3}$ The second one is a cryogenic target in which solid fuel is sustained by a low density porous foam shell. In this case it is produced by means of dipping the foam shell in liquid fuel prepared in a small vessel in a cryostat to fill up the liquid fucl in the foam shell and to cool it down to the freezing temperature. ${ }^{4-7}$

The weak point of the former target is that the fuel is covered by high atomic number atoms of glass which contribute to degrade the implosion performance. The latter target requires very fine control of procedures to make a uniform, spherical shell of fuel.

A technique to fabricate a high quality cryogenic target, with a plastic shell, which is considered a most suitable target for laser fusion, has been developed for implosion experiments by our laser system of "Gekko XII."

The cryostat is designed to fill the plastic shell at the laser firing position with high-pressure fuel gas up to 11 $\mathrm{MPa}$ at room temperature. The gas is filled by diffusion keeping a small pressure difference across the shell wall. ${ }^{8}$ The proof of principle to make a solid fuel layer in the plastic shell was already demonstrated by Henderson et al. in 1978 using a small plastic shell in a test chamber. ${ }^{9}$

The developed system can provide the uniform solid fuel layer inside the plastic shell with and without a low density foam layer by either the foam technique or an improved fast isothermal freezing (FIF) technique. ${ }^{10}$ When we use a plastic shell with a foam layer inside, a uniform fuel layer is obtained very easily. The system was intended to shoot one test target at room temperature and one cryogenic target every day.

\footnotetext{
a) On Ieave from Nihon Sannso Corporation, 4-230, Tsukagoshi, Saiwaiku,
} Kawasaki 210, Japan.
Details of the system and the performance are described in the following sections. Fabrication of the plastic shell with foam layer inside will be described elsewhere.

\section{INSTRUMENT}

The system to provide a cryogenic plastic shell target for the Gekko XII laser system is composed of two cryostats installed at the top and the bottom of the target chamber whose diameter is $1.8 \mathrm{~m}$. The main role of the upper cryostat is to supply a plastic shell to the laser firing position and that of the lower cryostat is to fill the target with fuel gas and to cool it down to a freezing temperature. The upper cryostat shown in Fig. 1 consists of a target positioner, a target-mount pole, a stationary support, and a vacuum system to evacuate helium gas used to cool down the target prior to the laser irradiation. In order to obtain a uniform temperature distribution, two liquid-helium tanks are located inside the target mount pole and in the stationary support. Main components of the lower cryostat illustrated in Fig. 2 are a gas-fill chamber with four windows, a cryogenic shroud, oil cylinders to actuate the gasfill chamber and the shroud, and a retraction system of the shroud for laser irradiation. The gas-fill chamber and the shroud are mounted independently on two concentric pipes. The shroud is cooled by liquid helium fed through a helical pipe connected to a liquid-helium reservoir located below the shroud. The exhausted helium flows to a helium recovery system through a gap between the inner pipe for the gas-fill chamber and the outer pipe for the shroud. Both cryostats are covered with room-temperature jackets to protect the equipments for plasma diagnostics from radiation cooling.

Figure 3 shows the assemblies of the gas-fill chamber and the cryogenic shroud. The gas-fill chamber which houses a stalk-mounted target during fuel filling consists of a quartz cylinder of $7-\mathrm{mm}$ i.d., $5-\mathrm{mm}$ thick and $15-\mathrm{mm}$ high and an invar protective cover with four windows of 5-mm diameter. The inner diameter of $7 \mathrm{~mm}$ was chosen for the gas-fill chamber not to hit the target when the gas-fill chamber is released from the upper mount pole. An indium ring of $1 \mathrm{~mm}$ in wire diameter was used to seal high-pressure gas. This system enables us to observe the 


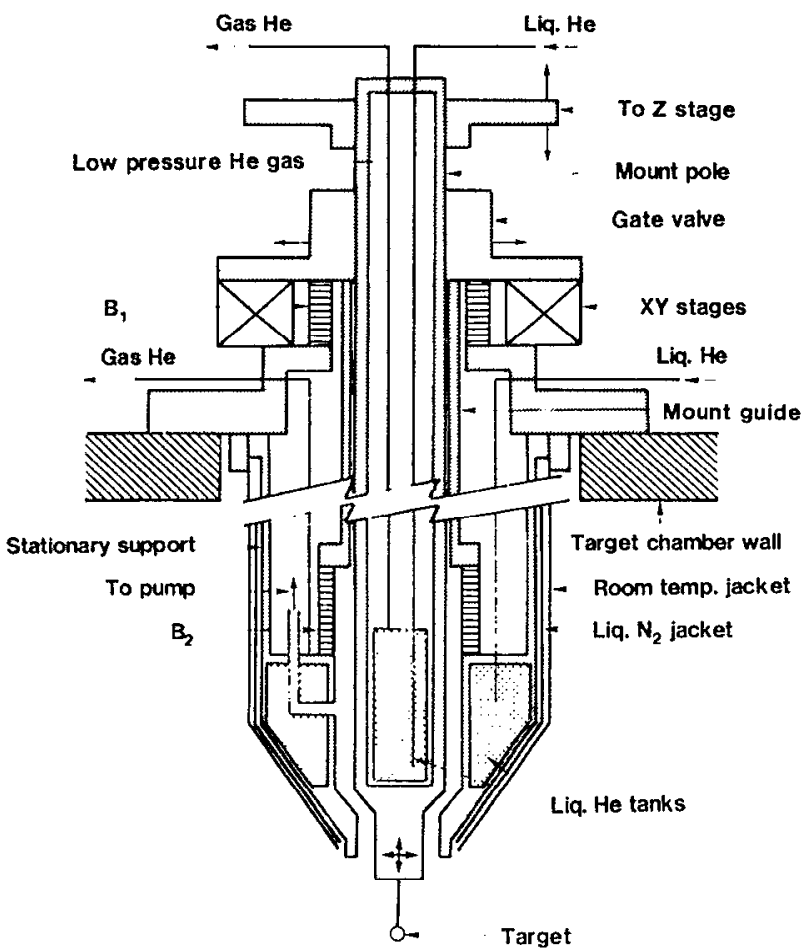

Stainless steel

$\mathrm{B}_{1}, \mathrm{~B}_{2}$ : Bellows

FIG. 1. Schematic diagram of upper cryostat (not to scale). The $z$-axis driver and liquid-nitrogen tanks are omitted for simplification. Their schematic view in linear scale is illustrated in Ref. 19.

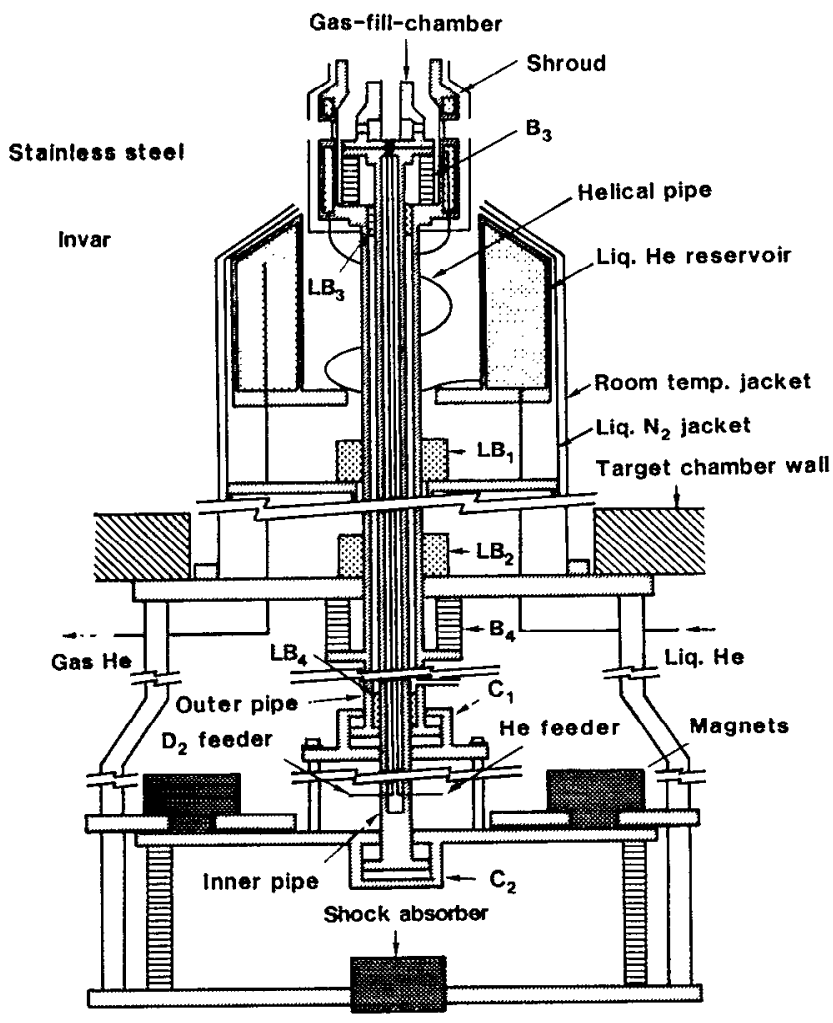

$B_{3}-B_{5}$ Bellows: $C_{1}, C_{2}$ Oil cylinder: $L B_{1}-L B_{4}$ Linear bearing

FIG. 2. Schematic diagram of lower cryostat (not to scale). Liquidnitrogen tanks are omitted for simplification.

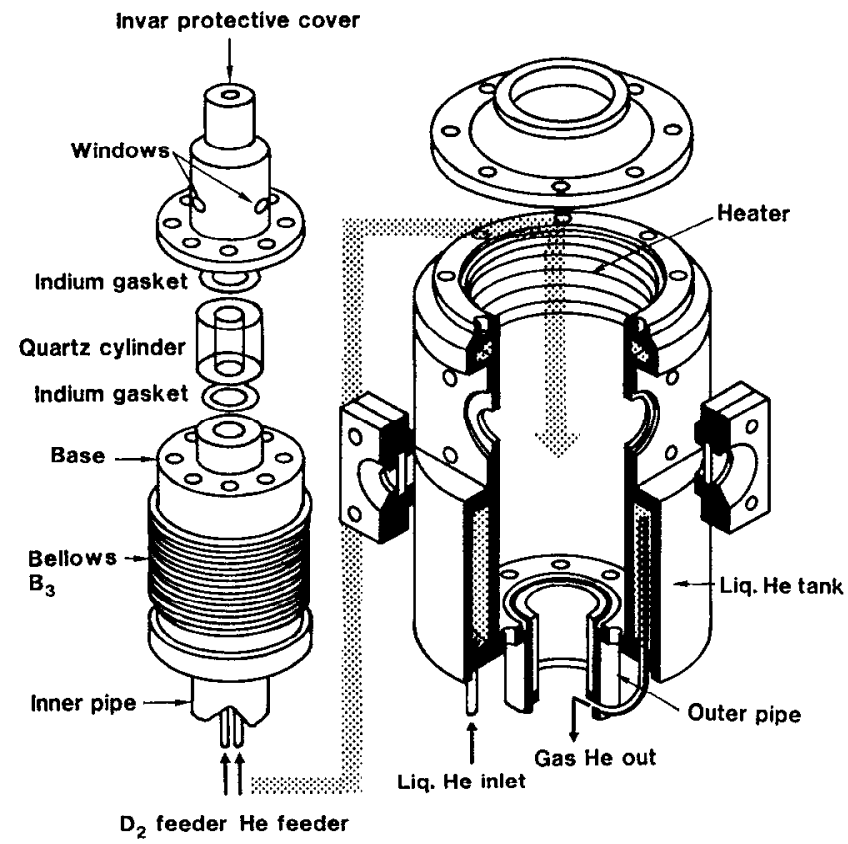

Gas-fill-chamber Cryogenic shroud

FIG. 3. Shroud assembly of the lower cryostat. Main parts are made of stainless steel except for the invar protective cover, the quartz cylinder, and four sapphire windows.

target during gas filling up to $11 \mathrm{MPa}$ through wide temperature excursions and no leakage took place in 30 repetitive operations.

The invar cover and the quartz cylinder are assembled on a stainless-steel base plate mounted at the top of the inner pipe. There are two gas feeders in the inner pipe. One is for supply of high-pressure deuterium gas and the other for replacement of the deuterium gas with helium before the disconnection of the gas-fill chamber from the target mount pole. The inner pipe is evacuated to prevent the deuterium feeder from plugging due to excess cooling.

The gas-fill chamber assembly is inserted into the cryogenic shroud which has four windows for target positioning. Two of the windows have larger openings to allow the instantaneous laser heating by an argon laser in the FIF technique. The gas-fill chamber in the shroud can travel along the $z$ axis with a stroke of $60 \mathrm{~mm}$ to allow positioning of the target at the laser focusing position. A stainless steel bellows $B_{3}$ is used to seal a gap between the inner pipe for the gas-fill chamber and the outer pipe for the shroud. The bellows is fixed on the bottom of the shroud using specially machined bolts with indium seals to hold the helium gas filled in the shroud. An electric heater is stuck on the inner surface of the shroud to heat it to room temperature in 10 $h$ after the laser shot.

In order to keep pressure on the indium seals constant from $300 \mathrm{~K}$ down to $8 \mathrm{~K}$, oil cylinders $C_{1}$ and $C_{2}$ are used to actuate the gas-fill chamber and the shroud. The cylinders are mounted on a head fiange of the retraction bellows $B_{5}$ to allow independent operation and simultaneous retraction of the shroud and the gas-fill chamber. The oil 
cylinder $C_{2}$ on the inner pipe is also used to lower the position of the gas-fill chamber enough for the target alignment.

Buckling of the long pipes was one of our major concerns in designing the lower cryostat unit. The outer pipe (a 30-mm o.d., 3-mm-thick, 1050-mm-long stainless-steel tube) is supported by two linear bearings (made of vespel SP-21, Du Pont Co.) at a level of a liquid-nitrogen tank $\left(L B_{1}\right.$ in Fig. 2) and that of a chamber mounting flange $\left(L B_{2}\right)$. The inner pipe of (20-mm o.d., 3-mm thick, 1650$\mathrm{mm}$ long) is supported at the top end by the outer pipe $\left(L B_{3}\right)$ and at the bottom end by the head flange of the bellows $\left(L B_{4}\right)$.

Main components of the retraction system are the 30$\mathrm{cm}$-diam vacuum bellows $B_{5}$, three holding magnets of $7.35 \mathrm{kN}$ in the total holding force and a shock absorber. The shock absorber of $3.46 \mathrm{~kJ}$ in one-stroke absorbing energy reduces landing shock of the moving assembly. This system can drive the retraction assembly of $48 \mathrm{~kg}$ in total mass with a mean acceleration of $10 \mathrm{~g}$ (g, gravitational acceleration) when the pressure in the bellows $B_{5}$ is 50 $\mathrm{kPa}$.

The target mount pole with the liquid-helium tank is made of a 30-mm-diam stainless-steel tube. The liquid tank is contacted softly with low-pressure helium to keep the moderate thermal connection between the helium tank and the pole. The load from the gas-fill chamber through the indium gasket is transferred to the wall of the target chamber through the pole and the $X, Y, Z$ stages. The stages are driven with step motors in 10- $\mu \mathrm{m}$ accuracy controlled by a microcomputer. Mechanical lock systems which fasten directly sliding stages with their bases are employed to reduce the load on delicate linear bearings and to increase reliability on sealing performance. The load on the seal of the shroud is directly transferred to the target chamber through the upper stationary support. A 60-mm-diam stainless-steel bellow $B_{2}$ is used to seal a gap between a target mount guide fixed on the $X, Y$, stages and an upper stationary supporter fixed on the target chamber. A vacuum between the target mount pole and the target mount guide is sealed by a rubber $\mathrm{O}$ ring at a level of the $X, Y$ stages.

Interferometers are installed in the original monitoring system of the Gekko XII laser for characterization of the solid fuel layer. The schematic of the system is shown in Fig. 4. The interferometric and normal target monitoring can be switched back and forth by inserting or pulling out a parallel-plate properly coated to yield interference images. Uniformity of solid or liquid fuel layer is displayed as concentric circular patterns.

If the target should fall off before the laser irradiation, intense laser beams may cause severe damage to optical components in the counterbeams. An automatic protection system was used to detect a fall of the target and inhibit the firing of the laser. ${ }^{11}$ This system can detect the target displacement of $100 \mu \mathrm{m}$ up to $40 \mathrm{~ms}$ prior to the laser irradiation.

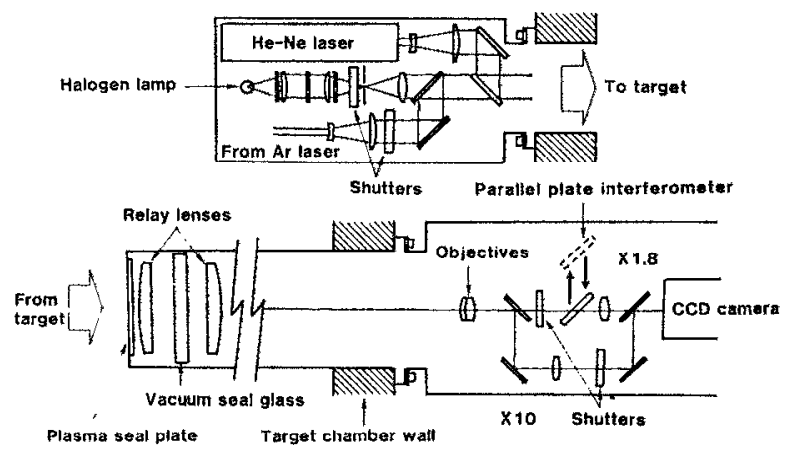

FIG. 4. Optical system for characterization and alignment of cryogenic target at firing position.

\section{OPERATION OF THE SYSTEM}

Either a polystyrene (PS) shell or a foam shell coated with a PS layer suspended with a $2-\mu \mathrm{m}$-diam polyester fiber on a glass stalk is mounted on the bottom end of the target mount pole. The indium gasket on the gas-fill chamber is renewed for each shot. The seal of the shroud is also replaced with a new one using a manipulator installed at a port perpendicular to the axis of the cryostat. The target is inserted into the chamber through an air lock gate and kept in a vacuum for a couple of hours to evacuate the air in the shell. The shroud and the gas-fill chamber are then forced to the upper cryostat to fill the target with deuterium gas. When argon gas for plasma diagnostics is required, the argon gas is filled in the gas-fill chamber for 2 $\mathrm{h}$ prior to deuterium gas filling.

The gas-fill chamber must be gradually pressurized to prevent collapsing of the shell due to the excess external pressure. When the pressure outside the shell increases at a rate $A(\mathrm{~Pa} / \mathrm{s})$, the pressure inside the shell $P(t)(\mathrm{Pa})$ is given by a permeation equation:

$$
\frac{d}{d t} P(t)=\Phi(T) \frac{S}{\delta r}[A t-P(t)],
$$

where $\Phi(T)$ denotes the permeability $\left(\mathrm{mol} \mathrm{m}{ }^{-1} \mathrm{~s}^{-1} \mathrm{~Pa}^{-1}\right), S$ the surface area $\left(\mathrm{m}^{2}\right), \delta r$ the wall thickness $(\mathrm{m})$, respectively. Through simple algebra, $P(t)$ is given as

$$
\begin{aligned}
& P(t)=A t-\frac{\delta r r A}{3 R T \Phi(T)}\left[1-\exp \left(\frac{-t}{\tau}\right)\right], \\
& \tau=\delta r r / 3 R T \Phi(T),
\end{aligned}
$$

where $r$ is the radius of the shell $(\mathrm{m}), R$ the gas constant $\left(8.314 \mathrm{~J} \mathrm{~mol}^{-1} \mathrm{~K}^{-1}\right), T$ the temperature of the shell $(\mathrm{K})$, respectively. The collapsing pressure $P_{\text {col }}$ of a thin spherical shell is given by ${ }^{12}$

$$
P_{\text {col }}=\left(\frac{\delta r}{r}\right)^{2} \frac{2 E}{\left[3\left(1-v^{2}\right)\right]^{0.5}},
$$

where $E$ is the Young's moduius and $v$ the Poisson's number, respectively. The pressure difference across the shell wall $A t-P(t)$ must be always less than $P_{\text {col }}$. The maximum allowable increase rate is then 


$$
A=B \frac{\delta r}{r^{3}} \frac{6 R T \Phi E}{\left[3\left(1-v^{2}\right)\right]^{0.5}}
$$

where $B$ denotes a safety factor. The strength of our PS shell is reported elsewhere. ${ }^{13}$ We set $B=0.25$ for daily operations. For instance, pressurizing rate $A$ for a $800-\mu \mathrm{m}$ diam PS shell with a $10-\mu \mathrm{m}$-thick wall was $0.25 \mathrm{MPa} / \mathrm{min}$.

After filling desired amount of gas, the system is cooled down below $8 \mathrm{~K}$ in $1.5 \mathrm{~h}$ with liquid helium served to each liquid-helium tank. Since the small gas-fill chamber is connected with room-temperature valves and pressure gauges through the long gas feeder pipe, the deuterium gas pressure in the gas-fill chamber becomes higher than that inside the shell when the gas-fill chamber is cooled. The deuterium gas in the chamber is gradually released in order to keep the pressure balance between inside and outside of the shell.

When the temperature of the gas-fill chamber becomes $50 \mathrm{~K}$, the residual deuterium gas in the chamber is gradually replaced, keeping the pressure constant, with cold helium gas to prevent condensation of the deuterium gas in the chamber. The helium gas pressure is controlled to be equal to the vapor pressure ${ }^{14}$ of deuterium in the shell in further cooling phase. After the deuterium in the shell freezes, the gas-fill chamber is lowered to expose the target to a low-pressure helium gas in the shroud. If the shell has sufficient strength to hold deuterium gas inside, the extra deuterium in the chamber is directly pumped out to be replaced with helium gas.

Since the shroud is forced to the upper stationary support during above mentioned process at room temperature and cooled down to a cryogenic temperature, strain which causes vibration of the target at retraction of the shroud may exist both at the upper and lower cryostats. The shroud is instantaneously detached from the upper stationary supporter to release the strain. This process is important not only to reduce vibrations of the target at the shroud retraction phase, but also to increase reliability on retraction timing because the shroud is strongly adhered to the upper cryostat with the indium seal. During this process, the pressure in the shroud is kept to be a few hundred $\mathrm{Pa}$ to maintain thermal connection between the target and the shroud.

When the capsule is a single PS shell, a uniform solid fuel layer is formed by heating the lower half of the shell with an intensity-graded $\mathrm{Ar}$ laser beam. The intensity of the beam is controlled so that sublimation of the solid deuterium takes place at the lower half of the shell and condensation of evaporated deuterium occurs at the upper half. When the capsule is a foam shell with a PS ablator, uniform liquid or solid fuel layer is formed by simply cooling it to a desired temperature. The uniformity of the fuel layer is characterized using interferometry since our foam shell is transparent when it is saturated with liquid deuterium. ${ }^{15}$

The evacuation of the helium gas in the shroud to less than $100 \mathrm{~Pa}$ starts at $2 \mathrm{~min}$ before the laser irradiation. The gas inside bellows $B_{5}$ is evacuated to $50 \mathrm{kPa}$ and the electric magnets are turned off to retract the shroud immedi-

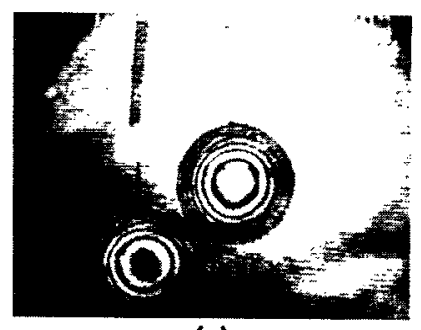

(a)

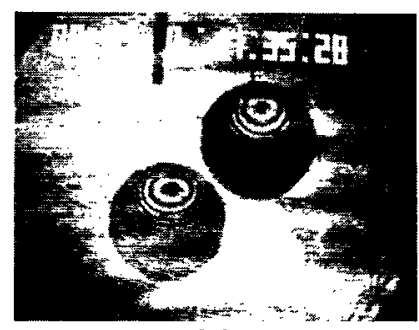

(c)

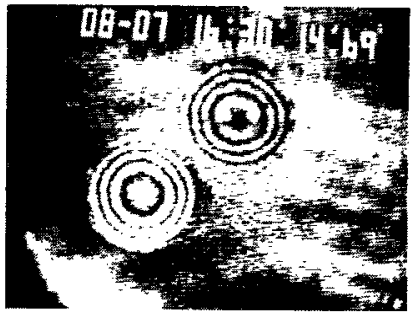

(b)
Dlameter, $758 \mu \mathrm{m}$

Wall thickness, $7.67 \mu \mathrm{m}$

Deuterium mass, $4.4 \mu g$

FIG. 5. Interference patterns of polystyrene shell (a) before gas fill, (b) at the gaseous phase of $40 \mathrm{~K}$ after gas fill, and (c) at the liquid phase of $19 \mathrm{~K}$. The fill pressure can be determined by comparing interference patterns (a) and (b).

ately before the laser irradiation. The target is shot after the shroud leaves the laser focusing corns but before the retraction assembly hits the shock absorber.

\section{EXPERIMENTAL RESULTS AND DISCUSSIONS}

\section{A. Operational}

The minimum load on the indium seal of $6 \mathrm{~mm}$ in ring diameter and $1 \mathrm{~mm}$ in wire diameter was $1 \mathrm{kN}$ for the prevention of leakage of $15-\mathrm{MPa}$ gas. In daily operation, the load was set to be $2.2 \mathrm{kN}$. Once the seal was completed at a room temperature, no leak took place even at cryogenic temperature. A force to release the seal at the cryogenic temperature was larger than the initial load on the seal by a factor of $1.2-1.5$.

The maximum deviation of target and the shroud window was $30 \mu \mathrm{m}$ at full load of $3.85 \mathrm{kN}$ on the indium seals. Vibration of the target at the release of the seal on the gas-fill chamber was less than $500 \mu \mathrm{m}$ and no accident of hitting the target took place.

Figure 5 shows interference patterns of a polystyrene shell (a) before gas fill, (b) at $40 \mathrm{~K}$, and (c) at $19 \mathrm{~K}$. The thickness of the liquid fuel layer was $0 \mu \mathrm{m}$ at the top and $30 \mu \mathrm{m}$ at the bottom. A uniform solid fuel layer was fabricated by heating the shell with the intensity-graded $\mathrm{Ar}$ laser beam. The details of this technique will be reported elsewhere.

\section{B. Estimation of vapor pressure in target}

Vapor pressure in the void of the cryogenic target when it is fired is an important parameter since implosion performance of the target depends strongly on the gas pressure in the shell. The vapor pressure in the shell is influenced by pressure of residual helium in the shroud just before the retraction of the shroud because low-pressure, 


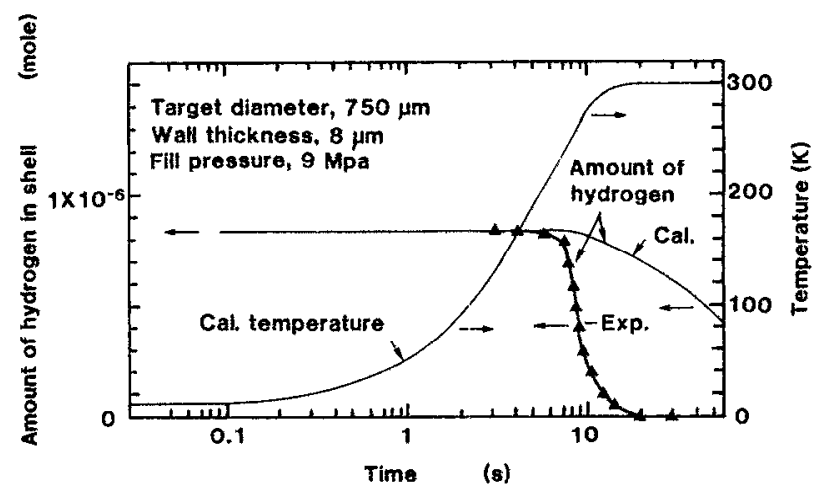

FIG. 6. Leakage of hydrogen in a polystyrene shell heated by thermal radiation. Calculation for temperature and amount of hydrogen in the shell are also shown.

low-temperature helium released from the cryostat continues to cool the target for a moment after the retraction. In order to estimate the vapor pressure in the shell, a polystyrene shell with solid fuel was exposed to thermal radiation in the same way as the actual laser irradiation. Phase change of the fuel and leakage of the gaseous fuel were observed using the interference telemicroscope. In this experiment normal hydrogen was also used because of well known optical properties and of different thermal properties.

The experimental results for the amount of hydrogen in the shell are shown in Fig. 6 with numerical calculations on temperature and the amount of hydrogen. The amount of hydrogen is calculated from the density obtained by the interferometric measurement. The gas density in the shell after evaporation was determined by counting the total number of fringes that appeared at the center of the shell during the leak process. The target used in the experiment was a $750-\mu \mathrm{m}$-diam shell with an $8-\mu \mathrm{m}$-thick wall filled with normal hydrogen of $9 \mathrm{MPa}$ at $300 \mathrm{~K}$. It took $2 \mathrm{~min}$ to evacuate the helium gas inside the shroud below a pressure where the target did not vibrate by the gas flow. When helium in the shroud was evacuated 2 min before the shroud retraction with an acceleration of $10 \mathrm{~g}$, all of the liquid hydrogen was evaporated at $t=0.9 \mathrm{~s}$ after the shroud retraction. Gas leakage due to diffusion started at 8 $s$ after the retraction. When the evacuation started $1 \mathrm{~min}$ before the shroud retraction, the liquid hydrogen evaporated completely at $9 \mathrm{~s}$ after the retraction and the leakage started at $18 \mathrm{~s}$ after the retractions. Melting of the solid hydrogen in the target was not observed in either case because of vibration of the target generated by the collision of the retraction assembly with the shock absorber.

The temperature of hydrogen was calculated by assuming that the target absorbed uniformly $100 \%$ of thermal radiation from the environment and the temperature in the target was uniform. Properties for hydrogens at low temperature were referred to in Wooly's report ${ }^{14}$ and in Roder's work ${ }^{16}$ and specific heat for PS was referred to in Ref. 17. Calculated results show that the deuterium ice melts in $200 \mathrm{~ms}$ and the liquid deuterium evaporates in $0.8 \mathrm{~ms}$ after the retraction, which agreed with experimental results. The
TABLE I. Results for fuel loading into polystyrene shells. Estimated tensile stress in the shell was also shown.

\begin{tabular}{|c|c|c|c|c|c|c|}
\hline Run & $\begin{array}{l}\text { Diam. } \\
(\mu \mathrm{m})\end{array}$ & $\begin{array}{l}\text { Wall } \\
\text { thick } \\
(\mu \mathrm{m})\end{array}$ & $\begin{array}{l}\text { Initial pres- } \\
\text { sure in fill } \\
\text { chamber } \\
(\mathrm{MPa})\end{array}$ & $\begin{array}{c}\text { Fill pressure } \\
\text { at roomi } \\
\text { temp. } \\
(\mathrm{MPa})\end{array}$ & $\begin{array}{c}\text { Estimated } \\
\text { stress at } \\
250 \mathrm{~K} \\
\left(\mathrm{~N} / \mathrm{m}^{2}\right)\end{array}$ & $\begin{array}{l}\text { Survive/ } \\
\text { explode }\end{array}$ \\
\hline 718 & 649 & 6.30 & 13.0 & 11.5 & $2.3 \times 10^{8}$ & Survived \\
\hline 726 & 769 & 7.60 & 10.0 & 8.5 & $1.7 \times 10^{8}$ & Survived \\
\hline 731 & 750 & 8.00 & 9.9 & 9.4 & $1.7 \times 10^{8}$ & Survived \\
\hline 802 & 688 & 8.00 & 13.0 & 11.3 & $1.9 \times 10^{8}$ & Exploded \\
\hline 807 & 758 & 7.67 & 11.5 & 11.1 & $2.1 \times 10^{8}$ & Survived \\
\hline 828 & 655 & 8.40 & 9.9 & 9.3 & $1.4 \times 10^{8}$ & Survived \\
\hline
\end{tabular}

calculated results indicated that the vapor pressure at the time of laser shooting was $600 \mathrm{~Pa}$.

\section{Strength of the shell at low temperature}

Tensile strength of our PS shell at a cryogenic temperature was another interest in designing this system. All of the used shells ranging $650-770 \mu \mathrm{m}$ in diameter and 6.3$8.0 \mu \mathrm{m}$ in wall thickness could hold deuterium gas of 1.6 $\mathrm{MPa}$ at $40 \mathrm{~K}$. The tensile stress in the PS wall was calculated to be $4.0 \times 10^{7}-6.5 \times 10^{7} \mathrm{~N} / \mathrm{m}^{2}$.

When the shell is continually heated, the pressure in the shell increases until permeation loss suppresses the increase. In order to know the maximum tensile stress which the shell can survive, the pressure in the shell was calculated using estimated temperature and the gas density. The calculation indicates that observable leakage takes place 8 $\mathrm{s}$ after the retraction when the target is heated to room temperature. Since permeation rate of deuterium through our shell wall at room temperature was almost the same as that reported by Scott et al., ${ }^{18}$ we used their temperature dependence of the permeation rate with a correction for mass dependence of diffusion. The observable leak in the calculation took place when the shell is heated to $250 \mathrm{~K}$. At this temperature the pressure of hydrogen in the shell is estimated to be $7.5 \mathrm{MPa}$ and the tensile stress in the PS wall is calculated to be $1.8 \times 10^{8} \mathrm{~N} / \mathrm{m}^{3}$ which is larger than tensile strength of PS at room temperature by a factor of 4 . Other experimental results are listed in Table I. Five shells in six could survive an estimated stress over $1.4 \times 10^{8}$ $\mathrm{N} / \mathrm{m}^{2}$ at $250 \mathrm{~K}$. This result is encouraging to design a portable, cryogenic cartridge which carries a tritium-filled PS shell target from a tritium fill system to the target chamber.

Experimental results showed that the leakage rate for pressurized hydrogen in the shell was much larger than the calculated one although the leak rate for the hydrogen less than $0.5 \mathrm{MPa}$ in fill pressure was almost same as the calculation. This would be attributed to enhanced diffusion due to elongation of the PS. In experiment 828 , the shell inflated by $10 \mu \mathrm{m}$ in diameter due to high inner pressure when it is heated to a room temperature.

'J. K. Hoffer and L. R. Foreman, J. Vac. Sci. Technol. A 7, 1161 (1989).

${ }^{2}$ R. Q. Gram, M. D. Wittman, C. Immesoete, H. Kim, R. S. Craxton, N. Sampat, S. Swales, G. Pien, J. M. Soures, and H. Kong, J. Vac. Sci. Technol. A 8, 3319 (1990). 
${ }^{3}$ V. Varadarajan, K. Kim, and T. P. Bernat, J. Vac. Sci. Technol. A 5, 2750 (1987)

T. Norimatsu et al., J. Vac. Sci. Technol. A 6, 3144 (1988).

${ }^{5}$ T. Norimatsu, Y. Kato, S. Nakai, and U. Kubo, J. Vac. Sci. Technol. A 7, 1165 (1989).

${ }^{6} \mathrm{H}$. Katayama, T. Norimatsu, Y. Kato, T. Yamanaka, and S. Nakai, Appl. Phys. Lett. 55, 2600 (1989).

${ }^{7} \mathrm{H}$. Katayama, T. Norimatsu, C. Chen, T. Yamanaka, and S. Nakai, J. Vac. Sci. Technol. A 9, 2140 (1991).

${ }^{8}$ R. A. Sacks and D. H. Darling. Nucl. Fusion 27, 447 (1987).

${ }^{9}$ T. M. Henderson, D. L. Melmoth, D. L. Musinski, T. R. Pattinson, and G. H. Wuttke, Adv. Cryo. Eng. 23, 699 (1978).

${ }^{10}$ K. Kim and D. L. Krahn, J. Appl. Phys. 61, 2729 (1987).

"M. Saito, S. Urushihara, K. Suzuki, K. A. Tanaka, T. Yamanaka, and S. Nakai, Rey. Laser Eng. 17, 721 (1989).

${ }^{12}$ K. Nakamura and T. Egusa, Design of Vessels (Ohm, Tokyo, 1966) (in Japanese).
${ }^{13}$ S. Kobayashi, T. Norimatsu, M. Nakai, K. A. Tanaka, T. Yamanaka, and S. Nakai, J. Vac. Sci. Technol. A 9, 150 (1991).

${ }^{14}$ H. W. Wooly, R. B. Scott, and F. G. Brickwedde, J. Res. Natl. Bur. Stand. 41, 379 (1948).

${ }^{15}$ M. Takagi, T. Norimatsu, T. Yamanaka, S. Nakai, and H. Ito, J. Vac. Sci. Technol. A 9, 820 (1991).

${ }^{16}$ H. M. Roder, G. E. Childs, R. D. McCarty, and P. E. Angerhofer, Nat. Bur. Stand. Technical Note 641 (1973).

${ }^{17}$ Japan Chemical Society, Kagakubinnrann (Maruzen, Tokyo, 1975) (in Japanese).

${ }^{18}$ L. A. Scott, R. G. Schneggenburger, and P. R. Anderson, J. Vac. Sci. Technol. A 4, 1155 (1986).

${ }^{19}$ T. Norimatsu, H. Ito, C. Chen, M. Yasumoto, M. Tsukamoto, K. A. Tanaka, T. Yamanaka, and S. Nakai, ILE Quartery Progress Report, 34, 3 (1991), ILE-QPR-90-34. 